Supporting Information

\title{
Synthesis and Pharmacological Evaluation of
}

\section{1-Phenyl-3-Thiophenylurea Derivatives as}

\section{Cannabinoid Type-1 Receptor Allosteric Modulators}

Thuy Nguyen, ${ }^{a}$ Thomas F. Gamage, ${ }^{a}$ Ann M. Decker, ${ }^{a}$ Daniel Barrus, ${ }^{a}$ Tiffany L. Langston, ${ }^{a}$ Jun-Xu Li, ${ }^{b}$ Brian F. Thomas, ${ }^{a}$ and Yanan Zhang ${ }^{a, *}$

${ }^{a}$ Research Triangle Institute, Research Triangle Park, North Carolina 27709, United States

${ }^{\mathrm{b}}$ Department of Pharmacology and Toxicology, University of Buffalo, the State University of New York, Buffalo, New York 14214, United States

\section{Table of Contents}

1. HPLC purity and retention time 
Compound purity by HPLC

\begin{tabular}{|c|c|c|}
\hline Compound & Retention time (min) & Purity (\%) \\
\hline 6 & 14.8 & 96.4 \\
\hline 7 & 15.0 & $>99 \%$ \\
\hline 8 & 18.5 & $>99 \%$ \\
\hline 9 & 13.6 & $>99 \%$ \\
\hline 10 & 13.8 & $>99 \%$ \\
\hline 11 & 17.3 & $>99 \%$ \\
\hline 12 & 16.4 & $>99 \%$ \\
\hline 13 & 18.5 & $>99 \%$ \\
\hline 14 & 16.9 & 97.8 \\
\hline 15 & 15.5 & $>99 \%$ \\
\hline 16 & 14.3 & 96.6 \\
\hline 17 & 12.1 & 96.0 \\
\hline 18 & 16.8 & 96.9 \\
\hline 19 & 17.0 & 97.4 \\
\hline 20 & 17.1 & 97.0 \\
\hline 21 & 17.3 & 95.7 \\
\hline 22 & 18.0 & 95.8 \\
\hline 23 & 18.0 & 98.4 \\
\hline 24 & 19.1 & 96.5 \\
\hline 25 & 19.8 & 98.2 \\
\hline 26 & 16.1 & 98.7 \\
\hline 27 & 16.8 & 96.2 \\
\hline 28 & 14.3 & 96.6 \\
\hline 29 & 16.4 & 99.6 \\
\hline 30 & 16.6 & 99.2 \\
\hline 31 & 16.4 & 99.3 \\
\hline 32 & 17.4 & 99.5 \\
\hline 33 & 12.4 & 98.7 \\
\hline 34 & 11.2 & 99.1 \\
\hline 35 & 11.5 & $>99 \%$ \\
\hline
\end{tabular}

